\title{
A large traumatic middle cerebral artery aneurysm in a child: case report and review of literature
}

\author{
Angelo Silva Neto ${ }^{1}$, Felipe Augusto Silva Alves ${ }^{2}$, Madson Caio Santos Dantas ${ }^{2}$, Felipe Roham \\ Vasconselo Lima², Gabriel Guedes da Cunha², Fernando Antônio de Araújo Moura ${ }^{3}$ \\ ${ }^{1}$ Integrated Medicine Department, \\ Federal University of Rio Grande do \\ Norte, Natal, Brazil \\ ${ }^{2}$ School of Medicine, Federal University \\ of Rio Grande do Norte, Natal, Brazil \\ ${ }^{3}$ Unity of Diagnostic Imaging, Hospital \\ Universitário Onofre Lopes, Natal, Brazil \\ To whom correspondence \\ should be addressed: Angelo

\begin{abstract}
A 6-year-old girl presented with a very large aneurysm of the distal branch of middle cerebral artery (angular artery). There was a previous history of mild traumatic brain injury. The presentation happened more than 5 weeks after the trauma with an atypical visual complaint. She was successfully treated by embolization and occlusion of the parental vessel. Recognizing pos traumatic aneurysm is a challenging in young child and must be remembered in patients with a recent traumatic event. Endovascular treatment is a good option when the occlusion of the artery is possible in the presence of a good collateral circulation.
\end{abstract} Silva Neto, MD,PhD

e-mail: angelorsn@gmail.com

Available at:

http://www.archpedneurosurg.com.br/

Keyworks: Dissecting aneurysm; middle cerebral artery; endovascular; pediatric aneurysms

\section{INTRODUCTION}

According to the literature, traumatic intracranial aneurysms are rare, making up less than $1 \%$ of all cases of intracranial aneurysms[1]. $25 \%$ of the reported traumatic brain aneurysms takes place in pediatric patients and this an even more unusual clinical entity [2].

We report here an extremely rare case of a 6-year-old girl with a large traumatic dissecting aneurysm of distal middle cerebral artery. We highlight in this case the clinical and radiological features with a brief review of literature.

\section{CASE REPORT}

A 6-year-old female patient was evaluated with a history of a progressive holocranial headache after a mild head trauma. The symptom became refractory to common analgesia. After about 40 days, the patient woke up with sudden bilateral amaurosis associated with worsening of the headache. Ophthalmological evaluation ruled out papilledema and other diseases. Initial neurological examination showed a patient with a Glasgow Coma scale of 15 and no signals of meningeal irritability. She did not show any additional deficits.

A Computed Tomography scan (CT-Scan) of the brain showed a small hyperdense rounded lesion in the posterior part of temporal lobe with enhancement after contrast. Angiotomography reveals an aneurysm of the angular artery, greater than $21.9 \mathrm{~mm}$ in diameter and the magnetic resonance shows an image suggestive of a vascular lesion in the region of the left transverse temporal gyrus, without hemorrhages. The shape of the aneurysm was suggestive of dissection (figure 1).

The patient was referred for endovascular treatment and characteristics of dissection of the arterial wall of the distal angular branch of the left middle cerebral artery were observed on angiography. After microcatheterization (Echelon 14 Medtronic $^{\circledR}$ ) the aneurysm showed an extremely slow flow with a large and wide neck. The 


\section{A large traumatic middle cerebral artery aneurysm in a child: case report and review of literature}

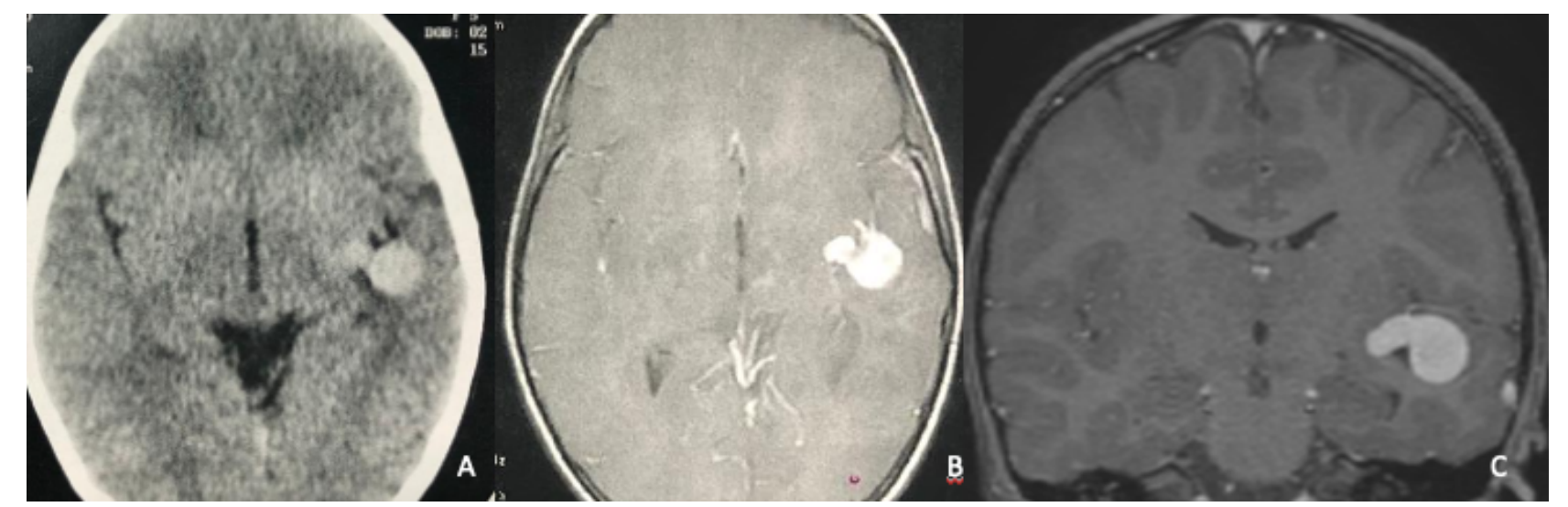

Figure 1 - A. axial computed tomography scan of the brain at the level of insular cortex showing a rounded lesion in the temporal transverse gyrus; B and C. Axial and coronal T1 weighted sequences showing an irregular vascular dilation in distal branch of left middle cerebral artery.

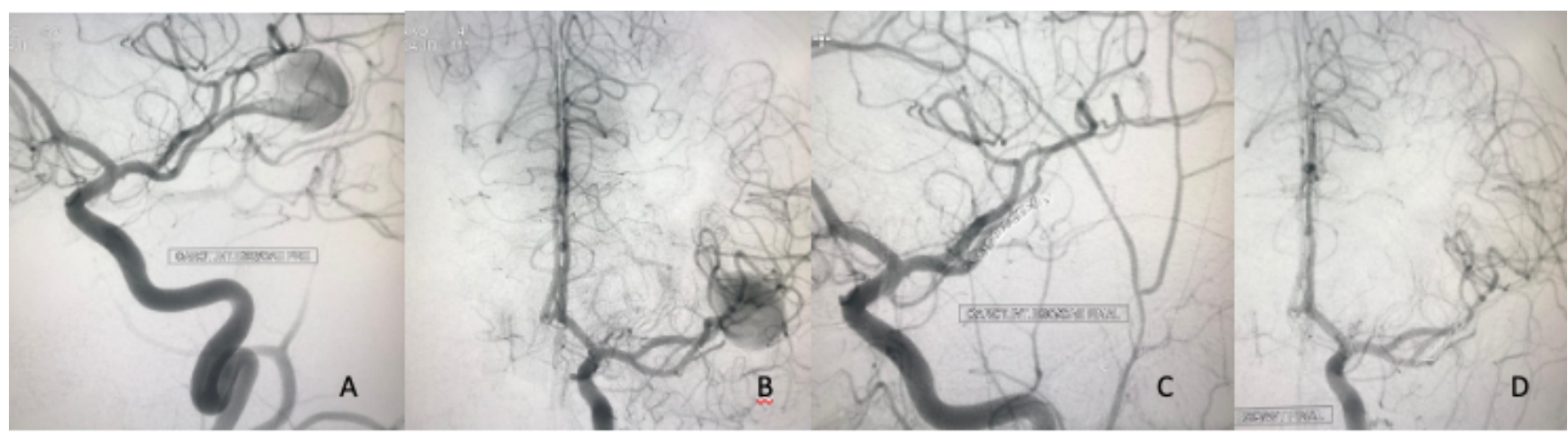

Figure 2 - A and B. cerebral angiography with left internal carotid injection showing the aneurysm situated at the angular artery. C and D. After coil embolization it is possible to realize the final perfusion by posterior parietal branches.

posterior parietal artery originated just before the aneurysm (figure 2). The lesion was successfully embolized with the use of four coils, with total occlusion of the angular artery (figure 2). The final arterial perfusion in the region of the angular gyrus was made by a posterior parietal branch. The patient evaluates with significant improvement in visual loss and without additional neurological deficits. She remained symptomatic free after 2 years of follow-up.

\section{DISCUSSION}

Pediatric aneurysms significantly differ from the adult aneurysms[3]. These differences are obvious when analyzing the clinical findings, the etiologies, and pathomechanisms of pediatric aneurysms origin[4]. Children with intracranial aneurysms require prompt treatment along with close observation as there is a high recurrence rate for subsequent cerebral ischemic events and their outcomes can be highly variable, ranging from a complete recovery to dead[5]. The difficult interpretation of symptoms in young children and the fact that symptoms of posttraumatic cerebrovascular injuries are unspecific often lead to misdiagnosis of these pathologies[6].

Cerebral artery dissections (CAD) can be categorized in two main groups: traumatic and spontaneous. More often spontaneous dissections are located on vertebral arteries and traumatic dissections in the internal carotid arteries[7]. According to Buckinghan et al. traumatic intracranial aneurysms in children are best categorized as penetrating and nonpenetrating aneurysms[8]. The last may be secondary to skull base fractures or a consequence of trauma against the falcine edge or more distally over a skull fracture. Falls and vehicle accident are the main causes, affecting more males( $60 \%$ ), probably due to a higher predominance of trauma among boys[9]. In contrast, adults $C A D$ literature have shown no sex predilections. Fullerton et al. discuss in a large review that a sexual factor can takes place on the pathogenesis of CAD in children[9].

Many conditions can be associated to arterial dissections, including diseases of connective tissue like Marfan syndrome, fibromuscular dysplasia and others[10]. 


\section{A large traumatic middle cerebral artery aneurysm in a child: case report and review of literature}

Otherwise healthy patients can also suffering traumatic dissections with no known risk factors. The majority of dissecting aneurysms have one entrance to the pseudolumen created by the dissection[4]. This property is responsible for the unstable clinical course[11].

The localization and the morphology of the aneurysm can give supports to a dissection origin as showed in this case. Typical sacular aneurysms used to occur in vessel bifurcations or places where the hemodynamic shear stress takes place[12]. In our case the aneurysm was located in a distal part of middle cerebral artery anatomy, with no substantial influence of hemodynamic stress. Giant aneurysms of MCA usually arise from proximal bifurcations (or trifurcations) and rarely occur at the distal MCA[13]. Angular artery is a distal branch of MCA that rises from the posterior part of Sylvian fissure and has a posterior direction[14].

The lack of a well-defined neck and the involvement of the parental vessel in dissecting aneurysms brings a great challenging when dealing with these cases[15]. Therefore, the definitive treatment usually involves techniques of occlusion of the proximal segment of the artery, surgical trapping or by-pass[16]. No standard recommendations have been established in the treatment of cerebral artery dissections[7, 11].

Pediatric patients treated conservatively have poor prognosis and should be enrolled in surgical or endovascular treatment $[8,11,17]$. Surgical clipping has the advantage of draining the hematoma around the aneurysm and the possibility of reconstruct the parent vessel, even though this maneuver requires a great ability in an irritated and inflamed brain[18]. In our case we decided in coil embolization rather than open surgery (trapping and sac evacuation) using a rationale in face of a difficult approach with higher risk of intraoperative rebleeding as consequence of high friability of this type of aneurysm.

Endovascular approach - Trapping with detachable balloon or occlusion with coils - has the advantage of no brain retraction, shorter anesthesia time and radiological control throughout the procedure[11]. Over the last years miniaturization of the devices and improvements in embolic materials have made it possible to perform safety endovascular procedures in infants as well as children[19]. Reconstructive strategies using stents and flow-diversion devices are another option when there is no possibly of total vessel occlusion and high risk of no collateral circulation. The potentially long term thrombotic risk is another question dealing with children with complex aneurysm treated by stents[20]. Recent data indicated safety and efficacy of flowdiverters in the treatment of pediatric aneurysms[21].

In the work of Chen et al. with focus on pediatric intracranial distal aneurysms, between 35 aneurysms they found 08 cases of pseudoaneurysm with $75 \%$ of traumatic origin. Middle cerebral artery was the more common location and $45.7 \%$ of the aneurysms were large or giant[18]. In children with a radiological find of a distal intracranial aneurysm and previous history of trauma the possibility of pseudoaneurysm must be highly suspected. In this situation the risk of hemorrhage is high manly due to the extremely thin and fragile wall of these aneurysms.

\section{CONCLUSION}

In summary, children with new neurological symptoms after a recent traumatic event must be enrolled to investigation of cerebral aneurysm. In this population the possibility of dissecting aneurysm at the distal circulation requires a prompt strategy with an accurate study of the affected artery and the collateral circulation. Endovascular embolization and parental vessel occlusion are options in these cases.

\section{DISCLOSURES}

\section{Ethical approval}

This study was performed in line with the principles of the Declaration of Helsinki. Approval was granted by the local Ethics Committee

\section{Consent to participate}

The patient gave consent to use his information and images for research proposes.

\section{Consent for publication}

The patient gave consent to use his information and images for publication.

\section{Conflict of interest}

The authors declare no conflicts of interest with respect to the content, authorship, and/or publication of this article.

Funding 


\section{A large traumatic middle cerebral artery aneurysm in a child: case report and review of literature}

This research received no specific grant from any funding agency in the public, commercial or not-for-profit sectors

\section{REFERENCES}

. 1. Koyama S, Kotani A, Sasaki J. Spontaneous dissecting aneurysm of the anterior cerebral artery: report of two cases. Surg Neurol. 1996;46(1):55-61.

2. Pinto $F C$, Valiengo $L$, Santos PP, Matushita $H$, Plese JP. Intracranial arterial aneurysms in childhood: case report. Arquivos de neuro-psiquiatria. 2006;64(3A):67680.

3. Xu R, Xie ME, Yang W, Gailloud P, Caplan JM, Jackson $\mathrm{CM}$, et al. Epidemiology and outcomes of pediatric intracranial aneurysms: comparison with an adult population in a 30-year, prospective database. J Neurosurg Pediatr. 2021:1-10.

4. Krings T, Geibprasert $\mathrm{S}$, terBrugge KG. Pathomechanisms and treatment of pediatric aneurysms. Childs Nerv Syst. 2010;26(10):1309-18.

5. Nash M, Rafay MF. Craniocervical Arterial Dissection in Children: Pathophysiology and Management. Pediatr Neurol. 2019;95:9-18.

6. Hejrati N, Ebel F, Guzman R, Soleman J. Posttraumatic cerebrovascular injuries in children. A systematic review. Childs Nerv Syst. 2020;36(2):251-62.

7. Urasyanandana $K$, Songsang $D$, Aurboonyawat $T$, Chankaew E, Withayasuk P, Churojana A. Treatment outcomes in cerebral artery dissection and literature review. Interv Neuroradiol. 2018;24(3):254-62.

8. Buckingham MJ, Crone KR, Ball WS, Tomsick TA, Berger TS, Tew JM, Jr. Traumatic intracranial aneurysms in childhood: two cases and a review of the literature. Neurosurgery. 1988;22(2):398-408.

9. Fullerton $\mathrm{HJ}$, Johnston $\mathrm{SC}$, Smith WS. Arterial dissection and stroke in children. Neurology. 2001;57(7):1155-60.

10. Bechan RS, van Rooij WJ. Endovascular treatment of a ruptured flow aneurysm of the heubner artery as part of a moyamoya collateral network in a young patient with an occluded middle cerebral artery. Interv Neuroradiol. 2014;20(6):791-5.

11. Chamoun RB, Jea A. Traumatic intracranial and extracranial vascular injuries in children. Neurosurg Clin N Am. 2010;21(3):529-42.

12. Silva Neto AR, Camara RL, Valenca MM. Carotid siphon geometry and variants of the circle of Willis in the origin of carotid aneurysms. Arquivos de neuro-psiquiatria. 2012;70(12):917-21.

13. Requejo $F$, Ceciliano A, Cardenas $R$, Villasante $F$, Jaimovich R, Zuccaro G. Cerebral aneurysms in children: are we talking about a single pathological entity? Childs Nerv Syst. 2010;26(10):1329-35.

14. Rhoton AL, Jr. The supratentorial arteries. Neurosurgery. 2002;51(4 Suppl):S53-120.

15. Kim M, Lee HS, Lee S, Park JC, Ahn JS, Kwon DH, et al. Pediatric Intracranial Aneurysms: Favorable Outcomes Despite Rareness and Complexity. World Neurosurg. 2019;125:e1203-e16.

16. O'Neal CM, Ernst GL, Hughes KL, Stephens TM, Hendrix $\mathrm{MC}$, Gross NL, et al. Reported incidence and treatment modalities of giant cerebral aneurysms in the pediatric population: A systematic review and illustrative case report. J Clin Neurosci. 2021;90:14-20.

17. Fleischer AS, Patton JM, Tindall GT. Cerebral aneurysms of traumatic origin. Surg Neurol. 1975;4(2):233-9.

18. Chen R, Zhang S, Guo R, Ma L, You C. Pediatric intracranial distal arterial aneurysms: report of 35 cases. Acta Neurochir (Wien). 2018;160(8):1633-42.

19. terBrugge KG. Neurointerventional procedures in the pediatric age group. Childs Nerv Syst. 1999;15(1112):751-4.

20. Vargas SA, Diaz C, Herrera DA, Dublin AB. Intracranial Aneurysms in Children: The Role of Stenting and FlowDiversion. J Neuroimaging. 2016;26(1):41-5.

21. Cherian J, Srinivasan V, Froehler MT, Grossberg JA, Cawley CM, Hanel RA, et al. Flow Diversion for Treatment of Intracranial Aneurysms in Pediatric Patients: Multicenter Case Series. Neurosurgery. 2020;87(1):53-62. 